\title{
A Volterra model of the greenhouse temperature using natural ventilation
}

\author{
J. K. Gruber*, F. Rodríguez ${ }^{* *}$, C. Bordóns *, J. L. Guzmán **, \\ M. Berenguel ${ }^{* *}$, E. F. Camacho* \\ * Dep. de Ingeniería de Sistemas y Automática, Universidad de Sevilla, C. de \\ los Descubrimientos s/n 41092 Sevilla, Spain. \\ E-mail: [jgruber, bordons, eduardo] @cartuja.us.es \\ ** Dep. de Lenguajes y Computación, Universidad de Almería, Ctra. \\ Sacramento s/n 04120 Almería, Spain. \\ E-mail: [frrodrig, joguzman, beren] @ual.es
}

\begin{abstract}
Model-based control techniques are commonly applied to control the greenhouse climate. As well-known, these techniques require accurate models for adequate results. Several first-principle models have been developed for the greenhouse climate control problem considering all the physical and physiological processes. However, these models are too complex to be used for control purposes. On the other hand, empirical models based on input/output real data allow to obtain better results and less complex model structures. In the Mediterranean areas the main problem is cooling the greenhouse and this leads to natural ventilation as a standard tool. This paper presents the development and the results of a Volterra model for the greenhouse temperature including the crop effect and using natural ventilation. (C) Copyright IFAC 2008.
\end{abstract}

\section{INTRODUCTION}

Crop growth requires greenhouse climate conditions achievable by means of advanced control techniques based on reliable models of the greenhouse climate. In the southeast (SE) of Spain, one of the main problems is greenhouse cooling by natural ventilation. During recent years, advanced control techniques have been developed, such as adaptive control (Sigrimis et al., 1999), feedforward control (Rodríguez et al., 2001), optimal control (van Straten et al., 2002), feedback linearizing control based on physical (Pasgianos et al., 2003) and empirical (Berenguel et al., 2006) models. This list of references is evidently limited and many important papers on the temperature control (Tantau, 1993; Seginer and Sher, 1993; Martin-Clouaire et al., 1996; Fuchs et al., 1997), etc. are not mentioned due to space constraints. Two widely differing strategies for modelling are those based on either first principles or input/output experimental data (Pearson, 1995). These techniques use a model of the greenhouse climate which links the output variable (temperature) to the control variable (vent position) and to the disturbances (mainly outside weather and crop). There exists a correlation between vent position and output temperature that can be ascribed to the ventilation rate. As a contributing factor, other researchers have identified this relationship by constructing semi-physical models, such as (Boulard and Baille, 1995) and (Kittas et al., 1997), and input/output empirical models (Rodríguez et al., 1999; Parra et al., 2004, 2006), and even by using an on-line estimator of the ventilation rate based on an unknown input observer with an output linearising feedback, as done by (Bontsema et al., 2006). The authors have previously used both physical and empirical models. In the first case, a greenhouse climate model based on energy balances was developed. Fundamentally, it is a dynamic model represented by a system of differential equations $d X / d t=f(X, U, P, V, C, t)$, with $X\left(t_{i}\right)=X_{i}$, where $X(t), U(t), P(t), V(t)$ and $C$ are respec- tively vectors of state variables, input variables, disturbances, system variables and system constants, $t$ is the time, $X_{i}$ is the known initial state at the initial time $t_{i}$. Hence, $f=f(t)$ is a nonlinear function based on mass and heat transfer balances. The number of equations describing the system characteristics depends on the greenhouse elements, the installed control actuators and the type of cultivation method. The physical processes included in the energy and mass balances are solar and thermal radiation absorption, heat convection and conduction, crop transpiration, condensation and evaporation (Rodríguez, 2002).

In order to model the natural ventilation rate, $\phi_{v e n}$, of a greenhouse equipped with sidewall and roof continuous actuators, some proposals from other researchers such as (Boulard and Baille, 1995) and (Kittas et al., 1997) have been tested. These models suggest that the ventilation process is induced by the stack effect due to thermal buoyancy (produced by the difference between internal and external air temperature, $X_{t, a}$ and $P_{t, e}$ respectively) and the wind effect due to the wind speed $\left(P_{w s, e}\right)$ action on the greenhouse structure. The best results were obtained with the following proposal of (Kittas et al., 1997)

$$
\begin{aligned}
\phi_{\text {ven }} & =c_{\text {ven }, d}\left[\left(2 c_{g} c_{\text {ven }, h} \frac{X_{t, a}-P_{t, e}}{\bar{X}_{t}}\right)\right. \\
& \cdot\left(\frac{V_{\text {ven }, \text { ar-lat }} V_{\text {ven }, a r-r f}}{\sqrt{V_{\text {ven }, \text { ar-lat }}^{2}+V_{\text {ven }, a r-r f}^{2}}}\right)^{2} \\
& \left.+\left(\frac{V_{\text {ven,ar-lat }}+V_{\text {ven }, a r-r f}}{2}\right)^{2} c_{\text {ven }, w} P_{w s, e}^{2}\right]+\phi_{\text {losses }}
\end{aligned}
$$

where $c_{v e n, d}$ is the discharge coefficient of the ventilators, $c_{v e n, w}$ is the wind pressure coefficient, $c_{g}$ is the acceleration of gravity, $\bar{X}_{t}$ is the mean absolute temperature, $c_{v e n, h}$ is the vertical distance between the midpoints of the lateral and roof vents. 
$V_{\text {ven,ar-lat }}$ and $V_{\text {ven,ar-rf }}$ are the areas of the sidewall and roof ventilation openings, given by:

$$
\begin{aligned}
& V_{\text {ven,ar-lat }}=c_{\text {ven,long-lat }} c_{\text {ven,wid-lat }} U_{\text {ven }} \\
& V_{\text {ven,ar-rf }}=2 c_{\text {ven,long-rf }} c_{\text {ven,wid-rf }} \sin \left(U_{\text {ven }} / 2\right)
\end{aligned}
$$

where $c_{\text {ven,long-lat }}$ and $c_{\text {ven,long-rf }}$ are the lengths of the lateral and roof ventilation, $c_{\text {ven,wid-lat }}$ and $c_{\text {ven,wid-rf }}$ are the widths of the lateral and roof ventilation, and $U_{\text {ven }}$ is the control signal of the ventilation openings in [\%]. The leakage term, $\phi_{\text {losses }}$, represents loss through leaks when the vents are closed, approximated by an imposed threshold between high and low wind speed. It was clear that the direct application of this kind of model to model-based control strategies entailed severe complications for techniques that required model inversion in order to obtain vent aperture $\left(U_{v e n}\right)$ from ventilation rate estimates (Rodríguez et al., 2001). Thus, empirical ventilation rate models were developed, both artificial neural-network based models (Rodríguez et al., 1999) and static empirical ones (Parra et al., 2006) to try to avoid the mentioned problems. In this last case, some studies were conducted in the greenhouse used in this work, where the well established logarithmic transformations of the mass balance equation for the decay-rate of a tracer gas $\left(\mathrm{N}_{2} \mathrm{O}\right)$ were employed by (Baptista et al., 1999), although that method cannot be used during crop production. One of the main results obtained by applying regression techniques to actual measurements on the effect of combined roof and sidewall ventilator actions was the fact that the expected ventilation rate per unit ventilator area and wind speed, followed an exponential expression of the combined aperture set point, $\phi\left(U_{v e n}\right)=P_{w s, e} \alpha U_{v e n}^{\beta}+\phi_{\text {losses }}$, where $U_{v e n}$ is the percentage aperture of the ventilators. The quantities $\alpha$ and $\beta$ are tuning parameters which, according to actual measurements, show subtle variations between leeward and windward ventilation. $\phi_{\text {losses }}$ is the calculated inherent ventilation leakage due to greenhouse aerodynamics and layout. Further studies were carried out in order to achieve an approximate, but well-tuned practical model, suitable for automatic control. Anyway, as pointed out by (Bontsema et al., 2006), since in practice the greenhouse climate is never in steady state, due to the external disturbances, the error is large due to neglecting the dynamic storage term.

In all the previous models, it can be seen how the models of the natural ventilation rate are quite difficult to obtain, so that, an approach based on Volterra models has been developed in order to find a trade-off between the difficulty for obtaining the model and the potential use for control purposes, applied for diurnal temperature control and applied to the typical parral greenhouse structure of the SE of Spain. Volterra models represent the logical extension of convolution models which have been applied successfully in linear model-based predictive control (MPC) (Doyle et al., 2002; Maner et al., 1996). These models exhibit generically a good behaviour and their structure can be exploited in the design of controllers, especially in the case of second order models. A second order Volterra model, with the truncation of terms (truncation orders $N_{1}$ and $N_{2}$ ), can be defined as:

$$
\begin{aligned}
y(k) & =h_{0}+\sum_{i=1}^{N_{1}} a(i) u(k-i) \\
& +\sum_{i=1}^{N_{2}} \sum_{j=1}^{N_{2}} b(i, j) u(k-i) u(k-j)
\end{aligned}
$$

which corresponds to a linear convolution model with a nonlinearity as additional and additive term, as described in section 2 . In that model $y(k)$ and $u(k)$ represent the last measured output and input to the system, respectively ( $k$ is the actual sampling instant). Notice that Volterra models have been frequently used to model bilinear systems in such a way that it seems to be a good idea to use this formulation for modelling greenhouse temperature dynamics, including the disturbances in the nominal formulation of second order Volterra models.

In a previous work, a preliminary Volterra model was developed to model the inside temperature of an empty greenhouse (without crop) in order to evaluate the behavior of this modelling technique for this kind of systems (Gruber et al., 2007). Several PRMS (Pseudo Random Multilevel Sequence) tests were performed using natural ventilation to obtain adequate data for identification purposes, because typical PRBS (Pseudo Random Binary Sequence) and RBS tests do not sufficiently excite nonlinear systems (Braun et al., 2001). The resulting model adequately fitted the real data but the number of parameters was excessively high. Furthermore, the crop has an important effect on the greenhouse temperature and thus it is a key factor to be included in the system model. Therefore, the present work faces the previous drawbacks reducing the number of model parameters and considering the crop effects.

The paper is organized as follows. It begins with materials and methods used where both equipment and the identification and modelling procedures are explained. Next, representative results are outlined. Finally, the conclusions section will summarize the achievements and propose intended applications.

\section{MATERIALS AND METHODS}

\subsection{Greenhouse}

The data were acquired in a Parral greenhouse located in Las Palmerillas Experimental Station (El Ejido, Almería, Spain, Figure 1). It is a symmetric curved flat roof greenhouse with five North-South oriented spans of $7.56 \times 23.2 \mathrm{~m}\left(877 \mathrm{~m}^{2}\right.$ total soil surface) and height from $2.8 \mathrm{~m}$ to $4.4 \mathrm{~m}$. The covering material is a 200-micron thick PE film, laid on a galvanized steel structure $^{1}$. The control actuators installed in the greenhouse are automated flap roof and rolling lateral continuous ventilators, the former with a maximum aperture angle of $45^{\circ}$ and the latter with $37 \mathrm{~m}$ length and $1.2 \mathrm{~m}$ aperture. Both have insect screens installed in the ventilation openings. Soil temperature measurements were made using semiconductor sensors at different depths, i.e., on both side of the mulch, immediately under the soil surface layer and at a depth of $50 \mathrm{~mm}$. The greenhouse air temperature thermoresistance sensor and the air relative humidity capacitive sensor were placed at the top of the crop. A meteorological station was installed outside at a height of $6 \mathrm{~m}$ for measurements of temperature, relative humidity, solar and photosynthetically active radiations, rain, and wind speed and direction. Some additional crop data were logged, i.e., substrate water content, water supply, amount of drainage, electrical conductivity of the substrate, plant transpiration measured with an electronic weight, leaf temperature and $\mathrm{CO}_{2}$ concentration. A uniform sampling time of one minute was established.

\footnotetext{
1 http://aer.ual.es/CJPROS/engindex $\cdot$ php?Opcion=5
} 

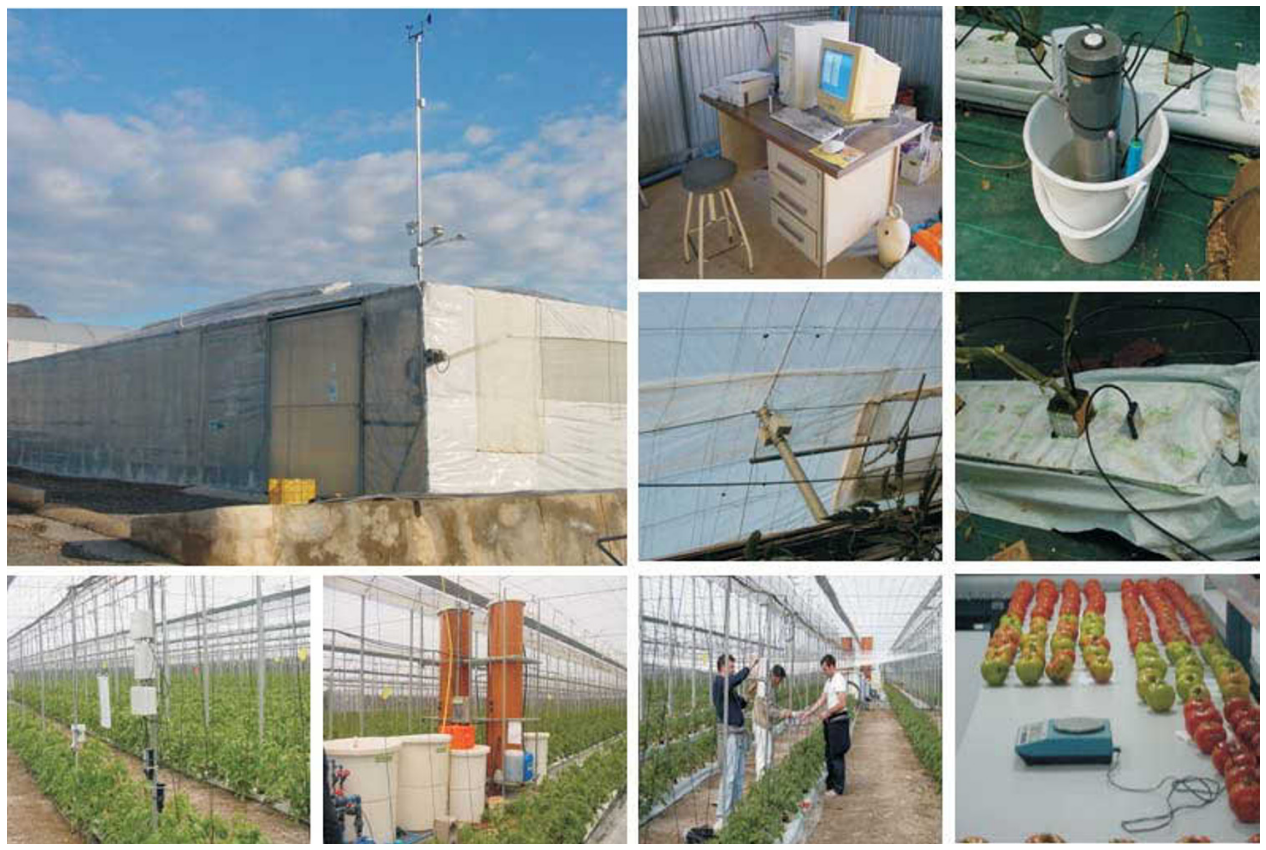

Fig. 1. Greenhouse used for the experiences.

\subsection{Models, data and parameter identification}

As the main objective of the work presented in this paper was to evaluate the potential use of Volterra models to account for the main dynamics describing changes in inside air temperature to outside weather using only natural ventilation, the data used for identification purposes was collected with crop (tomatoes) inside the greenhouse (April/May, 2006). The influence of the crop was taken into account as a disturbance to the greenhouse temperature. The mentioned disturbance was modeled by means of the the Leaf Area Index (LAI). Thus, the main variables considered for modelling purposes are:

- Output: $X_{t, a}$ inside air temperature.

- Input: $a_{l a t, r f}$ aperture of the roof and lateral ventilations.

- Disturbances: $P_{t, e}$ outside temperature, $P_{w s, e}$ outside wind speed, $P_{t, s s}$ soil surface temperature, $P_{s o l, e}$ outside global solar radiation, $P_{L A I}$ Leaf Area Index.

During the identification process, additional inputs were tested (not included in this document), as the product $a_{\text {lat }, r f} P_{w s, e}$, but no large improvements in the parameter identification stage was detected while the number of parameters did increase. Moreover, the selection of these modulated variables will prevent the use of model predictive controllers.

A second order truncated Volterra models that represented in equation (3). In the case of autoregressive (AR) models, the structure is:

$$
\begin{aligned}
y(k) & =h_{0}+\sum_{i=1}^{N_{y}} h_{1}(i) y(k-i)+\sum_{i=1}^{N_{1}} a(i) u(k-i) \\
& +\sum_{i=1}^{N_{2}} \sum_{j=i}^{N_{2}} b(i, j) u(k-i) u(k-j)
\end{aligned}
$$

where $h_{0}$ is the offset and $h_{1}(\cdot), a(\cdot)$ and $b(\cdot)$, the AR parameters, the linear parameters and the nonlinear second order parameters, respectively. Second order AR terms have not been included, as the selection allows obtaining adequate results. In the theoretical case the upper limit of the convolution sum will be $\infty$, but in a stable system as the greenhouse, the number of terms can be truncated (sum limits $N_{y}, N_{1}$ and $N_{2}$ ) to reduce the number of parameters to identify, in such a way that $h_{1}(i)=$ $0, \forall i>N_{y}, a(i)=0, \forall i>N_{1}, b(i, j)=0, \forall i>N_{2}, j>N_{2}$. Diagonal models are often used to reduce the number of parameters to estimate $(b(i, j)=0, \forall i \neq j)$, but in the case treated in this paper only non-diagonal second order Volterra models have been used. Notice that, although the disturbances could be distinguished from the manipulable variables (for instance, when using these models for control purposes), there is no difference between them for identification purposes, and then, both manipulable variables and disturbances will be denoted by $u(\cdot)$ in this work without loss of generality.

As the system under consideration is MISO (Multiple Input Single Output), the model in the AR case (in the non-AR case $\left.h_{1}(i)=0, \forall i\right)$ is given by:

$$
\begin{aligned}
y(k) & =h_{0}+\sum_{i=1}^{N_{y}} h_{1}(i) y(k-i)+\sum_{l=1}^{n} \sum_{i=1}^{N_{1, l}} a_{l}(i) u_{l}(k-i) \\
& +\sum_{l=1}^{n} \sum_{i=1}^{N_{2, l}} \sum_{j=i}^{N_{2, l}} b_{l}(i, j) u_{l}(k-i) u_{l}(k-j)
\end{aligned}
$$

In order to identify the parameters of the Volterra models, data in the period from 19 April to 02 May, 2006 have been used (Figure 2, only a period of 5 days is shown, time scale in days), while data from 03 May to 07 May, 2006 have been used for validation purposes (Figure 3). Obviously, more data should be necessary to obtain more reliable results, but the selected data are enough for assessing the validity of the technique for greenhouse temperature modelling. The sample time was 2 minutes and the data were adequately filtered through first order filters before using them for calibration purposes.

Before performing the identification and validation, the filtered data are also normalized, 


\begin{tabular}{|c|c|c|c|c|c|c|c|c|c|c|c|c|c|c|}
\hline Name & Method & Order & $a_{\text {lat }, r f}$ & $P_{t, e}$ & $P_{w s, e}$ & $P_{\text {sol, }, e}$ & $P_{t, s s}$ & $P_{L A I}$ & $X_{t, a}$ & $\sum$ parameters & $\varepsilon_{i d}$ & $\varepsilon_{\text {val }}$ & $1 \mathrm{~b}, \mathrm{ub}$ & $\mathrm{A}, \mathrm{b}$ \\
\hline \multirow{2}{*}{0} & \multirow{2}{*}{ lsq } & $1^{\mathrm{st}}$ & 30 & 1 & 10 & 5 & 10 & 1 & 0 & \multirow{2}{*}{234} & \multirow{2}{*}{0.6024} & \multirow{2}{*}{0.6994} & \multirow{2}{*}{$=[],=[]$} & \multirow{2}{*}{$=[],=[]$} \\
\hline & & $2^{\text {nd }}$ & 15 & 1 & 10 & 0 & 0 & 0 & 0 & & & & & \\
\hline \multirow{2}{*}{ A } & \multirow{2}{*}{ fmin } & $1^{\text {st }}$ & 30 & 1 & 10 & 5 & 10 & 1 & 0 & \multirow{2}{*}{234} & \multirow{2}{*}{0.7710} & \multirow{2}{*}{0.9450} & \multirow{2}{*}{$\neq[], \neq[]$} & \multirow{2}{*}{$=[],=[]$} \\
\hline & & $2^{\text {nd }}$ & 15 & 1 & 10 & 0 & 0 & 0 & 0 & & & & & \\
\hline \multirow{2}{*}{ B } & \multirow{2}{*}{ fmin } & $1^{\mathrm{st}}$ & 20 & 1 & 2 & 5 & 10 & 1 & 0 & \multirow{2}{*}{99} & \multirow{2}{*}{0.8297} & \multirow{2}{*}{1.1358} & \multirow{2}{*}{$\neq[], \neq[]$} & \multirow{2}{*}{$=[],=[]$} \\
\hline & & $2^{\text {nd }}$ & 10 & 1 & 2 & 0 & 0 & 0 & 0 & & & & & \\
\hline \multirow{2}{*}{ E } & \multirow{2}{*}{ fmin } & $1^{\mathrm{st}}$ & 20 & 1 & 2 & 5 & 10 & 1 & 0 & \multirow{2}{*}{99} & \multirow{2}{*}{0.8909} & \multirow{2}{*}{1.1680} & \multirow{2}{*}{$\neq[], \neq[]$} & \multirow{2}{*}{$\neq[], \neq[]$} \\
\hline & & $2^{\text {nd }}$ & 10 & 1 & 2 & 0 & 0 & 0 & 0 & & & & & \\
\hline \multirow{2}{*}{$\mathrm{C}$} & \multirow{2}{*}{ ar } & $1^{\mathrm{st}}$ & 1 & 1 & 1 & 1 & 1 & 1 & 1 & \multirow{2}{*}{13} & \multirow{2}{*}{0.5976} & \multirow{2}{*}{0.7357} & \multirow{2}{*}{$=[],=[]$} & \multirow{2}{*}{$=[],=[]$} \\
\hline & & $2^{\text {nd }}$ & 1 & 1 & 1 & 1 & 1 & 0 & 0 & & & & & \\
\hline D & $\operatorname{ar}$ & $1^{\mathrm{st}}$ & 2 & 2 & 2 & 2 & 2 & 2 & 2 & 30 & 0.5961 & 0.7264 & $=[1,=[]$ & $=[],=[]$ \\
\hline & al & $2^{\text {nd }}$ & 2 & 2 & 2 & 2 & 2 & 2 & 0 & & & & {[],} & \\
\hline
\end{tabular}

Table 1. Main numerical results
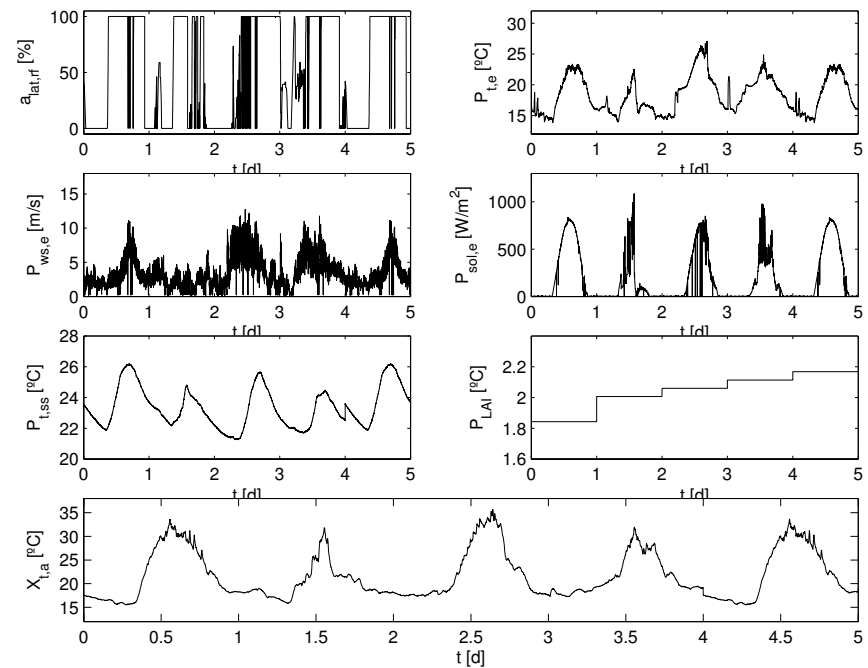

Fig. 2. Raw data for identification.
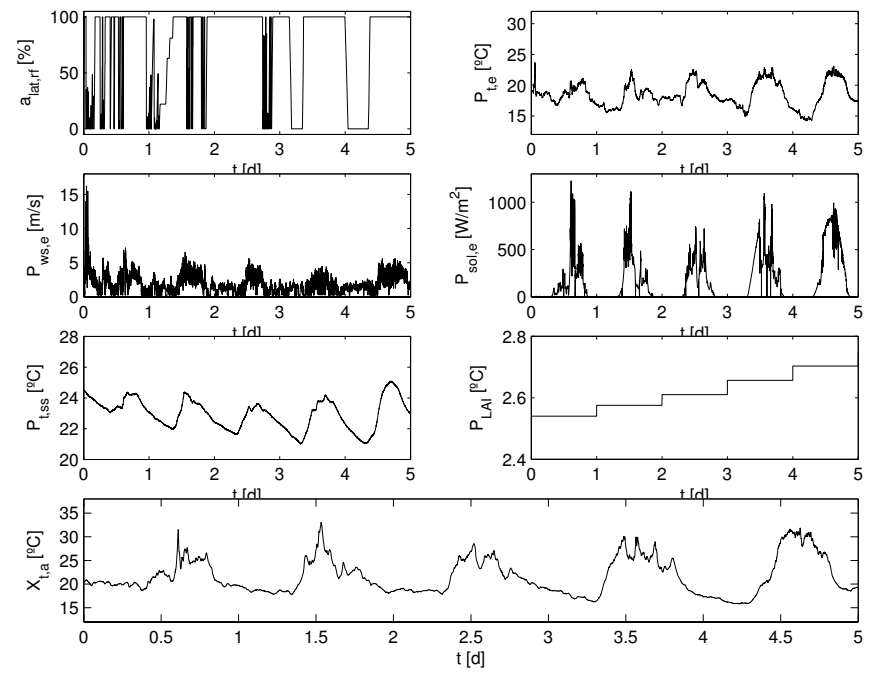

Fig. 3. Raw data for validation.

$$
V_{i d}^{n o r}=\frac{V_{i d}-V_{i d}^{\text {min }}}{V_{i d}^{\text {max }}-V_{i d}^{\text {min }}} ; V_{v a l}^{\text {nor }}=\frac{V_{v a l}-V_{i d}^{\text {min }}}{V_{i d}^{\text {max }}-V_{i d}^{\text {min }}}
$$

where $V$ is each one of the used input/disturbance/output signals both in the identification (id) and validation ( $\mathrm{val}$ ) data sets, supra-index min means the minimum value in that set and $\max$ the maximum one. In this way, the identification data are normalized to the interval $[0,1]$ and the validation data to an interval close to that. With these normalized values, the output of the Volterra model is also normalized $\left(y^{\text {nor }}\right)$, in such a way that the real output is given by $y=y^{n o r}\left(X_{t, a-i d}^{\max }-X_{t, a-i d}^{\min }\right)+$ $X_{t, a-i d}^{\min }$. To identify the parameters of the Volterra models, both least squares methods and constrained nonlinear optimization using sequential quadratic programming have been used.

\section{REPRESENTATIVE RESULTS}

In this section several representative results are shown, both in tabular and graphical ways. Both non-AR and AR models have been identified and validated. The meaning of the abbreviations used in Table 1 are: lsq (least squares method), fmin (constrained nonlinear optimization), ar (AR model), lb, ub (lower and upper bounds of the parameters) A, b (matrices defining linear constraints of the form $A x \leq B), \varepsilon_{i d}, \varepsilon_{v a l}$ (mean square error for identification and validation:

$$
\varepsilon=\frac{\sum_{i=1}^{n}\left(X_{t, a}(i)-\hat{y}(i)\right)^{2}}{n}
$$

where $\hat{y}$ is the output of the model. Table 1 shows the main results of the identification and validation stages.

\subsection{Non-AR models}

Identification test 0: the first identification was performed using the least squares method. One of the initial problems was to select the truncation orders for the six variables influencing the greenhouse inside temperature. Due to this reason, in a first step identifications were performed in such a way that for each variable a long truncation order was selected, while the truncation order for the rest was zero. In these identifications the truncation orders of the second order terms were also zero. In a second step, six new identifications were carried out to determine the second order truncation orders, using the truncation orders for the linear terms selected in the first step. Finally, once the truncation orders were determined, the identification using the least-squares method was done. The used truncation orders are shown in Table 1, as well as the number of parameters (234, including the offset) and the mean square errors.

Identification test A: As the plots of the parameters obtained in the previous case did not show a consistent convergence (many parameters have noisy profiles), constraints have been included in the identification process, then using nonlinear optimization techniques. The number of parameters is the same than in the 


\begin{tabular}{cccccccc}
\hline Order & Const. & $a_{l a t, r f}$ & $P_{t, e}$ & $P_{w s, e}$ & $P_{s o l, e}$ & $P_{t, s s}$ & $P_{L A I}$ \\
\hline \multirow{2}{*}{$1^{\text {st }}$} & $\mathrm{lb}$ & - & - & 0 & 0 & 0 & - \\
\cline { 2 - 7 } & $\mathrm{ub}$ & 0 & - & - & - & - & - \\
\hline \multirow{2}{*}{$2^{\text {nd }}$} & $\mathrm{lb}$ & 0 & - & - & - & - & - \\
\cline { 2 - 7 } & $\mathrm{ub}$ & - & - & 0 & - & - & - \\
\hline & & Table 2 & Constraints for identification $\mathbf{A}$ &
\end{tabular}

Table 2. Constraints for identification $\mathbf{A}$

previous case (see Table 1) but with the constraints shown in Table 2. The results of the identification and validation are shown in Table 1. With the constraints, the linear parameters have more reasonable values, and the parameters corresponding to the second order terms that are not zero are close to the main diagonal (not shown for the sake of space).

Identification test B: In the previous experience, it was detected that several of the linear terms parameters (specially those related to $P_{w s, e}$ and $a_{l a t, r f}$ ) were equal to zero, in such a way that the corresponding truncation orders could be decreased to 20 and 2, respectively. In the same way, the truncation order of the second order terms of $P_{w s, e}$ were reduced to 2 , providing a total number of 99 parameters. The same constraints were used and the mean square errors were slightly higher than in test $\mathbf{A}$.

Identification test $\mathbf{E}$ : In the three previous cases, the linear parameters associated to variable $a_{\text {lat,rf }}$ did not achieve coherent values, in such a way that additional conditions were added. The same truncation orders and constraints than in the $\mathbf{B}$ case were used, but it was imposed that $a_{a_{\text {lat }, r f}}(k) \geq a_{a_{\text {lat }, r f}}(k-$ 1) for $k=2, \ldots, 20$, this conditions being quite easily implementable in the nonlinear constrained optimization problem. In an analogous way the conditions $a_{P_{\text {sol, },}}(k) \leq a_{P_{\text {sol,e }}}(k-1)$ for $k=$ $2, \ldots, 5$ and $a_{P_{t, s s}}(k) \leq a_{P_{t, s s}}(k-1)$ for $k=2, \ldots, 10$ for the outside global solar radiation and the soil surface temperature were used. A plot of the results of the identification and validation is shown in Figure 4. The resulting linear parameters are shown in Figure 5, while the second order term parameters are shown in Figure 6. It can be seen that the linear terms corresponding to the variables $P_{s o l, e}, P_{t, s s}$ and $a_{l a t, r f}$ are smooth curves. A further reduction of the truncation order for the corresponding variables is not possible anymore. Furthermore, with the imposition of the additional conditions for the linear parameters, the nonlinear parameters of the model input $a_{l a t, r f}$ show a coherent and reasonable shape. Diagonal models were also tested, but the mean square errors increased.

\subsection{AR models}

Two identification tests are shown using AR models with nonlinear open loop identification.

Identification test $\mathbf{C}$ : In a first step, all the truncation orders were set to 1 for the linear parameters of the six variables influencing the greenhouse temperature. For the disturbance $P_{L A I}$ no second order terms were used, for the remaining five variables a nonlinear truncation order of 1 was chosen. With regards to the AR terms, a truncation order equal to 1 was used for the linear part and 0 for the nonlinear one. The offset has been also added, with a total of 13 parameters (Table 1).

Identification test D: Finally, a second identification is shown where the truncation orders for the linear and nonlinear parameters related to the input and disturbance variables are set to 2, except for the second order terms of $P_{L A I}$ which were not used as in the previous identification. The AR part of the model has
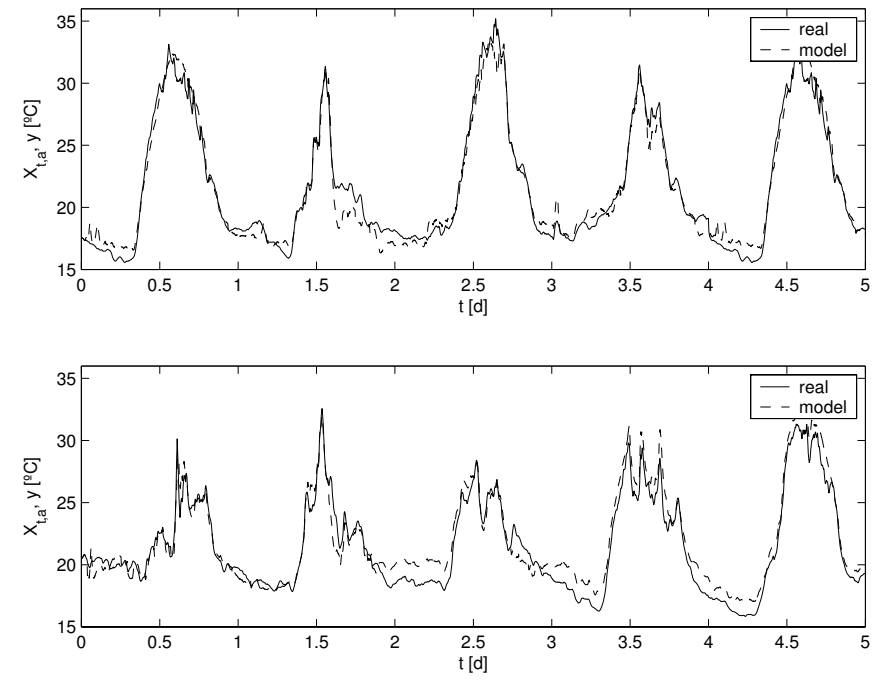

Fig. 4. Test E: identification (up) and validation (down) results
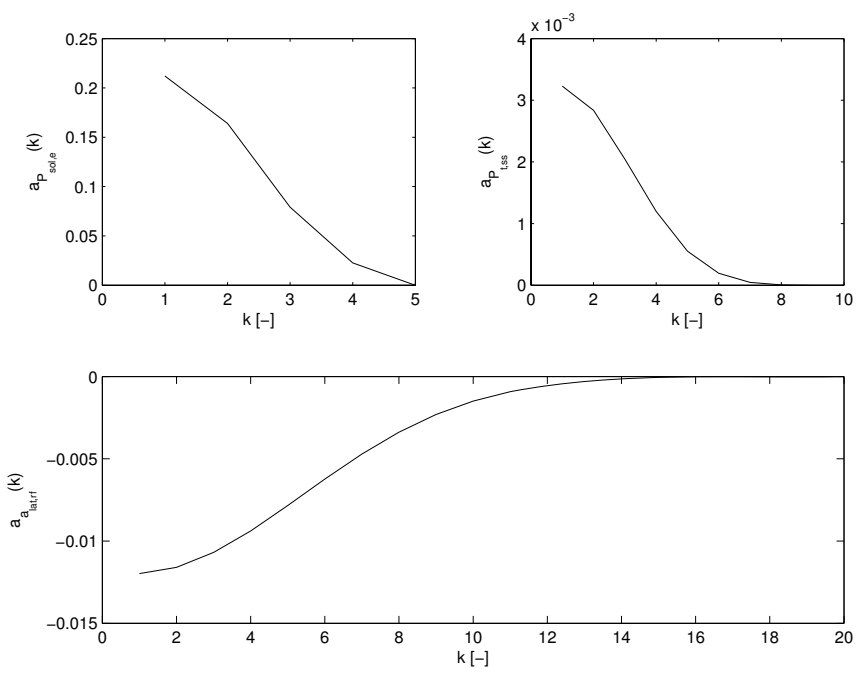

Fig. 5. Test E: some linear parameters

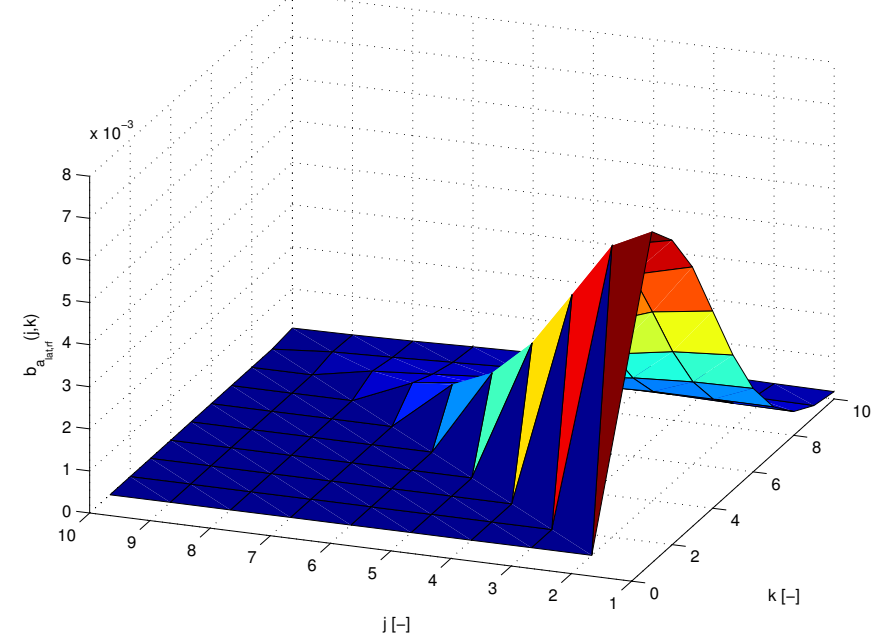

Fig. 6. Test E: some second-order parameters

a truncation order with 2 parameters in the linear part and 0 parameters in the second-order terms (nonlinear AR terms have been neglected). Again, the offset is included, providing a total 
of 30 parameters. The main results are shown in Table 1 and in Figure 7 (plot of the results of the identification and calibration with the AR model). It can be seen that the mean square error is reduced to $\varepsilon_{i d}=0.5961$ and $\varepsilon_{v e r}=0.7264$.
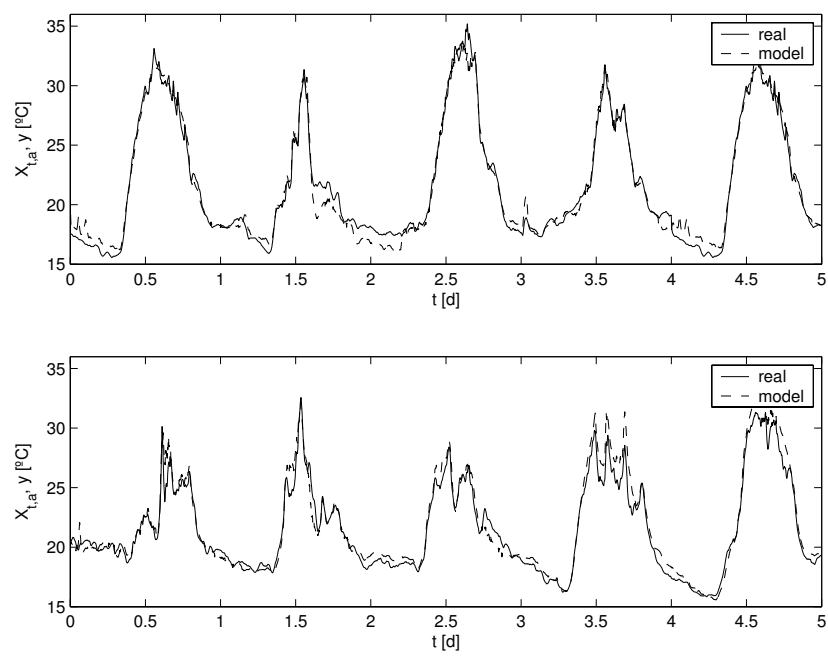

Fig. 7. Test D: identification (up) and validation (down) results

\section{CONCLUSIONS}

This paper has presented results on the application of Volterra models for the modelling of greenhouse temperature evolution using natural ventilation and including the crop effect. The main interest was to see how these models cope with the nonlinear behaviour inherent in the relationship between temperature and vents aperture, through the ventilation rate, which is one of the most difficult dynamics to be modelled in the greenhouse as discussed in the introduction section. Future works will include the application of model predictive control schemes for greenhouse temperature control using the models obtained in this work.

\section{ACKNOWLEDGEMENTS}

This work was supported by the Spanish CICYT-FEDER grants DPI2004-07444-C04-01/04 and DPI2007-66718-C0401/04, by Fundación Cajamar and by the Consejería de Innovación, Ciencia y Empresa de la Junta de Andalucía.

\section{REFERENCES}

B.J. Baptista, B.J. Bailey, J.M. Randall, and J.F. Meneses. Greenhouse ventilation rate: Theory and measurements with tracer gas techniques. J. Agri. Eng. Res. 72, pp. 363-374, 1999.

M. Berenguel, F. Rodríguez, J.L. Guzmán, D. Lacasa, and J. Pérez Parra. Greenhouse diurnal temperature control with natural ventilation based on empirical models. Acta Horticulturae 179, pp. 205-211, 2006.

J. Bontsema, E.J. van Henten, J. Hemming, J. Budding, and T. Rieswijk. On-line estimation of the ventilation rate of greenhouses. ISHS Acta Horticulturae 718, 2006.

T. Boulard and A. Baille. Modelling of air exchange in a greenhouse equipped with continuous roof vents. J. Agri. Eng. Res. 61, pp. 37-48, 1995.

M.W. Braun, D.E. Rivera, and A. Stenman. A model-ondemand identification methodology for nonlinear process systems. Int. J. of Control, 74(18), pp. 1708-1717, 2001.
F.J. Doyle, R.K. Pearson, and B.A. Ogunnaike. Identification and Control Using Volterra Models. Springer, London, 2002.

M. Fuchs, E. Dayan, D. Shmuel, and Y. Zipori. Effects of ventilation on the energy balance of a green house with bare soil. Agricultural and Forest Meteorology, 86, pp. 273-282, 1997.

J. K. Gruber, F. Rodríguez, C. Bordóns, J. L. Guzmán, and M. Berenguel. A survey of computer-based approaches for greenhouse climate management. IFAC Agricontrol, pages 41-46, 2007.

C. Kittas, T. Boulard, and G. Papadakis. Natural ventilation of a greenhouse with ridge and side openings: Sensitivity to temperature and wind effects. Trans. of the ASAE. 40(2), pp. 415-425, 1997.

B.R. Maner, F.J. Doyle, B.A. Ogunnaike, and R.K. Pearson. Nonlinear model predictive control of a simulated multivariable polymerization reactor using second-order volterra models. Automatica, 32(9), pp. 1285-1301, 1996.

R. Martin-Clouaire, P. J. Schotman, and M. Tchamitchian. A survey of computer-based approaches for greenhouse climate management. Acta Horticulturae, 406:409-423, 1996.

J. Pérez Parra, E. Baeza, J.I. Montero, and B.J. Bailey. Natural ventilation of parral greenhouses. Biosystems Engineering 87(3), pp. 355-366, 2004.

J. Pérez Parra, M. Berenguel, F. Rodríguez, and A. RamírezArias. Ventilation rate models of mediterranean greenhouse for control purposes. Acta Horticulturae 179, pp. 197-204, 2006.

G.D. Pasgianos, K.G. Arvanitis, P. Polycarpou, and N. Sigrimis. A nonlinear feedback technique for greenhouse environmental control. Computers and Electronics in Agriculture, 40, pp. 153-177, 2003.

R.K. Pearson. Nonlinear input/output modelling. J. Proc. Control, 5(4), pp. 197-211, 1995.

F. Rodríguez, M.R. Arahal, and M. Berenguel. Application of artificial nn for greenhouse climate modeling. European Control Conference, 1999. Karlsruhe, Germany.

F. Rodríguez, M. Berenguel, and M.R. Arahal. Feedforward controllers for greenhouse climate control based on physical models. European Control Conference, 2001. Porto, Portugal.

F. Rodríguez. Modelling and hierarchical control of greenhouse crop production. $\mathrm{PhD}$ thesis, University of Almera, Spain, 2002.

I. Seginer and A. Sher. Optimal greenhouse temperature trajectories for a multi-state-variable tomato model, chapter in: The computerized greenhouse, pages 153-172. Academic Press, 1993.

N. Sigrimis, P.N. Paraskevopoulos, K.G. Arvanitis, and N. Rerras. Adaptive temperature control in greenhouses based on multirate-output controllers. Proc. 14th IFAC World Congress. pp. 571-576, 1999. Beijing, China.

H. J. Tantau. Optimal Control for plant production in greenhouse, chapter in: The computerized greenhouse, pages 139152. Academic Press, 1993.

G. van Straten, L.G. van Willengenburg, and F. Tap. The significance of crop co-states for receding horizon optimal control of greenhouse climate. Control Eng. Practice, 10, pp.625-632, 2002. 